\title{
Effect of stress coping ability and working hours on burnout among residents
}

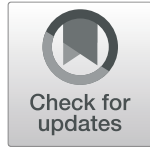

Saori Kijima ${ }^{1,2}$, Kazuya Tomihara ${ }^{3}$ and Masami Tagawa ${ }^{1 *}$ (D)

\begin{abstract}
Background: Burnout among residents leads to interruptions in training and even to exit from programs. Despite the implementation of working hour restrictions in the U.S. in 2013, the high rate of burnout remains a serious problem. Therefore, we analyzed Japanese residents' burnout, training conditions, and associated factors, especially stress coping ability, which could become an evidence base for creating guidelines of programs and working environments.

Methods: In total, 37 teaching hospitals were randomly selected, and all residents in the third and fifteenth months of a residency program at these hospitals were targeted for this research. We analyzed the residents' burnout rates, associated factors, and interactions using response data from a self-administered questionnaire consisting of the Japanese versions of the Maslach Burnout Inventory (MBI) and the Sense of Coherence (SOC) scale, as well as items asking about their training environments, gender, and age.

Results: Overall, 48 (49.5\%) of 97 residents in 18 teaching hospitals (62 and 35 in the third and fifteenth months, respectively), whose average working hours were $63.3 \mathrm{~h}$ per week, were judged as having burnout, among whom, 33 (53.2\%) and 15 (42.9\%) had burnout in the third and fifteenth months, respectively. Logistic regression analysis indicated that working hours and 10 items on the SOC scale (SOC10) were significant factors of burnout. Two-way analysis of variance revealed that working hours was a significant variable for the MBI-emotional exhaustion score and SOC10 in the third and fifteenth months, respectively. Regarding the MBI-cynicism and professional efficacy scores, the SOC10 was a significant variable in both the third and fifteenth months. In addition, the high SOC group (SOC10 > 45) showed higher personal efficacy under longer working hours.

Conclusion: About half of the Japanese residents were judged as having burnout as early as the third month of training under regulations of working $40 \mathrm{~h}$ per week. Individual stress coping ability and working hours were found to be significant factors for burnout. Residents with high stress coping ability exhibited more personal efficacy with more working experiences, which suggests that the SOC scale could be a valuable tool to help foster a suitable training environment.
\end{abstract}

Keywords: Burnout, Maslach burnout inventory, Sense of coherence, Resident, Working hours

\footnotetext{
* Correspondence: Masami@m3.kufm.kagoshima-u.ac.jp

${ }^{1}$ Center for Innovation in Medical and Dental Education, Graduate School of

Medical and Dental Sciences, Kagoshima University, 8-35-1 Sakuragaoka,

Kagoshima 890-8544, Japan

Full list of author information is available at the end of the article
}

(c) The Author(s). 2020 Open Access This article is licensed under a Creative Commons Attribution 4.0 International License, which permits use, sharing, adaptation, distribution and reproduction in any medium or format, as long as you give appropriate credit to the original author(s) and the source, provide a link to the Creative Commons licence, and indicate if changes were made. The images or other third party material in this article are included in the article's Creative Commons licence, unless indicated otherwise in a credit line to the material. If material is not included in the article's Creative Commons licence and your intended use is not permitted by statutory regulation or exceeds the permitted use, you will need to obtain permission directly from the copyright holder. To view a copy of this licence, visit http://creativecommons.org/licenses/by/4.0/ The Creative Commons Public Domain Dedication waiver (http://creativecommons.org/publicdomain/zero/1.0/) applies to the data made available in this article, unless otherwise stated in a credit line to the data. 


\section{Background}

Postgraduate residency programs in the United States, Canada, and many other countries now aim to foster medical doctors who possess competencies as professionals. To accomplish this goal, qualified residency programs under governmental or professional regulations and guidelines provide residents with opportunities for essential clinical training as well as necessary support and a proper working environment.

Burnout is defined as a prolonged work-related response to emotional and interpersonal stressors on the job, and has been associated with withdrawal, intention to leave the job, job turnover, loss of productivity, and quality of work [1-3]. Maslach and Jackson developed the Maslach Burnout Inventory (MBI) [1], which is composed of three subscales that evaluate the burnout dimensions of emotional exhaustion, cynicism (depersonalization), and professional efficacy (personal accomplishment). The MBI has been used for evaluating emotional state and judging burnout [3].

Medical and health professionals, among others, might easily fall into burnout because of excessive demand for mental energy in the process of assisting patients [4]. Previous studies using the MBI have reported that $76 \%$ of internal medicine residents in the United States in 2001 [5] and 61\% of residents in Australia in 2001 [6] were judged as having burnout.

Maslach et al. analyzed the causes of burnout based on interviews with company administrators and workers, and reported that burnout was the result of factors such as social environmental problems, overtime work, a lack of discretionary power, inadequate remuneration, dissatisfaction with work, poor human relations, and the uncontrollability of work [7]. As for residents' burnout, risk factors and effective interventions have repeatedly been discussed [3]. Several studies have reported that inadequate remuneration [8] and frequent calls [9] and night duty [10] are promoting (or worsening) factors for burnout, and that 80 or fewer hours of work per week [11], counseling [12, 13], the existence of somebody to consult with, such as those in mentoring programs $[14,15]$, stress-relieving opportunities [16, 17], and mindfulness-based skills programs [18] are preventive (or relieving) factors for burnout.

In addition to the training environment, individual factors such as marriage [19] and childcare [20] have been reported to reduce the factors of burnout. Men have reported significantly more job- and patient-related burnout than women [21], whereas women are more likely than men to report frequently 'experiencing fatigue' and 'burnout from work' [22]. In addition, Tsele et al. and Cliiers reported that individual stress coping ability affects burnout among health professionals [23, 24].

Antonovsky proposed the concept of salutogenesis, and developed the Sense of Coherence (SOC) scale to evaluate individual stress coping ability [25]. The SOC scale is a self-administered questionnaire composed of the following three subscales: the extent to which a person comprehends the world (comprehensibility), perceives manageability in whatever situation that arises (manageability), and finds meaning in life (meaningfulness). A previous study involving 79 nurses using the SOC scale, MBI, and Beck's Depression Inventory indicated that people with a low SOC score were at higher risk of burnout and depression [23]. Tartas et al. reported that SOC scores examined prior to medical school admission were significantly correlated with occupational stress and burnout among medical doctors after graduation [26].

In the United States, the Accreditation Council for Graduate Medical Education implemented working hour regulations on residency programs to prevent overwork, resulting in an average of 80 working hours per week [27-29]. Although the frequency of burnout decreased from 36 to $77 \%$ to $25-69 \%$ [28, 30-33], burnout remains a serious problem. Therefore, in addition to uniform restrictions on working hours, residency programs require evidence-based guidelines for fostering effective working environments.

The aim of the present study was to reveal the frequency of burnout among Japanese residents and the level of emotional exhaustion, cynicism, and professional efficacy, which characterize a burned out person, at different training phases, and to reveal environmental and individual factors related to burnout. Furthermore, this study aimed to explore the influence of individual stress coping ability on burnout and working hours.

\section{Methods}

\section{Targets and data collection}

All postgraduate residency programs in Japan are qualified by the Ministry of Health, Labour and Welfare. It is mandatory for residents to practice internal medicine, general surgery, community medicine, and emergency medicine in a 2-year program. We randomly selected 37 teaching hospitals of various sizes that operate qualified residency programs based on geological distribution (16 hospitals/prefecture) from all over Japan.

To collect data at the early and later phases of training, all residents in the third and fifteenth months at these hospitals were targeted for this research.

Next, we created a self-administered questionnaire consisting of the following:

1) Japanese version of the MBI-General Survey (MBIGS) ${ }^{\mathrm{mm}}$ (Mind Garden, Inc. Menlo Park, CA, USA) [34]. The MBI-GS is a scale composed of 16 items rated on a seven-point Likert scale. The Japanese version of the MBI-GS was created and validated by 
Kitaoka et al. [35]. Kitaoka granted the authors of the present study permission to use the validated Japanese version.

2) Japanese version of the SOC scale. The SOC scale is composed of 13 items rated on a seven-point Likert scale. The Japanese version of the SOC scale was created and validated by Togari et al. [36]. Yamazaki (a coauthor of that study) granted the authors of the present study permission to use the validated Japanese version.

3) Items regarding influential factors in the training environment, including frequency of night duty [10], working hours [11], existence of somebody to consult with $[14,15]$, having ways to release one's stress $[16,17]$, feeling adequately rewarded for one's own work [8], and work controllability [7], and

4) Personal characteristics such as gender and age.

We distributed the printed questionnaire by mail with an exploratory description of this research and its ethical approval, and collected responses from July to September 2014.

\section{Data analysis}

We confirmed the independence of the MBI and SOC scales by exploratory factor analysis with promax rotation using item scores of both scales, and then excluded the SOC items that were classified into the same factors as the MBI subscale for the subsequent analysis. We confirmed the internal consistencies of the MBI, MBI subscales, and SOC scale using Cronbach's $\alpha$ coefficient.

The cut-off and abnormal scores for each MBI subscale, which evaluate different features of burnout, as indicated by the MBI-GS were as follows:

- MBI-GS subscale emotional exhaustion (MBI-EX) score: 16 or higher

- MBI-GS subscale cynicism (MBI-CY) score: 11 or higher

- MBI-GS subscale professional efficacy (MBI-PE) score: 23 or lower

Individual burnout judgment varies in the literature, so we adopted the following criteria validated by Schaufeil et al. [37]: an MBI-EX score of 16 or higher and/or an MBI-CY score of 11 or higher. These criteria can discriminate between clinical burned out and not-burned out employees [37], and have been used in previous burnout studies $[5,6]$.

Next, we analyzed the frequency of burnout calculated with the number of residents judged by these criteria, MBI-EX, MBI-CY, and MBI-PE scores, influential factors related to these scores, and differences in training phases using the $t$-test, chi-squared test, and logistic regression analysis. To assess the effects of stress coping ability on burnout, the respondents were divided into low and high SOC groups using the average SOC scores since a cutoff score for stress coping ability has not been reported. Correlation and two-way analysis of variance was then carried out to analyze the relationship between MBI-EX, MBI-CY, and MBI-PE scores, SOC scores, and working hours. SPSS (version 21; IBM, New York, NY, USA) was used for all data analyses.

\section{Results}

In total, 107 residents (response rate: 28.2\%) at 18 teaching hospitals in 11 prefectures responded to the questionnaire. After excluding invalid responses, such as choosing the same options, data from 97 residents (41 residents in hospitals with 500 beds or more, 36 in hospitals with 300-499 beds, and 20 in hospitals with 299 beds or less; 62 in the third month of their residency program and 35 in the fifteenth) were used for the analysis.

Table 1 shows the respondents' demographic data and working environments. The residents' average ages in the third and fifteenth months were 26.7 and 27.6 years, respectively, average frequency of night duty was 3.6 times per month, and average number of working hours per day was 11.5 , which is equivalent to $63.3 \mathrm{~h}$ per week.

\section{Confirmation of scales}

Exploratory factor analysis with promax rotation of the Japanese versions of the MBI and SOC scale using data from the 97 respondents indicated a six-factor structure (Table 2). Factors 1, 2, and 4 had items identical to the MBI-PE, MBI-EX, and MBI-CY detected in the original English version. The three-factor structure of the original version of the $\mathrm{SOC}$ scale did not detect these in the present analysis, and two items on the SOC scale were classified into factor 1 (MBI-PE); one item had a loading of over 0.4 for factor 4 (MBI-CY) and factor 6 . These three items were excluded, and thus, 10 items of the SOC scale (SOC10) were used for the analysis.

Cronbach's $\alpha$ coefficients for the MBI-EX, MBI-CY, and MBI-PE were $0.91,0.88$, and 0.89 , respectively. Cronbach's $\alpha$ coefficient for the SOC10 was 0.81 .

\section{MBI-GS subscale scores, burnout frequency, and influential factors}

As shown in Table 3, the residents' mean MBI-EX, $-\mathrm{CY}$, and -PE scores were 15.2, 7.7, and 16.4, respectively.

Among 97 respondents, 48 (49.5\%) were judged as having burnout (Table 4). The frequencies of burnout in the third and fifteenth months were 53.2 and $42.9 \%$, respectively, with no significant difference. The frequencies of burnout among men and women were 49.2 and $50.0 \%$, respectively; gender was not a significant factor. 
Table 1 Baseline demographics of the survey respondents

\begin{tabular}{|c|c|c|c|c|c|c|}
\hline & \multicolumn{2}{|c|}{ Third month } & \multicolumn{2}{|c|}{ Fifteenth month } & \multicolumn{2}{|l|}{ Total } \\
\hline & $\mathrm{n}$ & $(\%)$ & $\mathrm{n}$ & (\%) & $n$ & $(\%)$ \\
\hline Respondent & 62 & $(100)$ & 35 & $(100)$ & 97 & $(100)$ \\
\hline Male & 37 & $(59.7)$ & 26 & $(74.3)$ & 63 & $(64.9)$ \\
\hline \multirow[t]{2}{*}{ Female } & 25 & $(40.3)$ & 9 & $(25.7)$ & 34 & $(35.1)$ \\
\hline & Mean & (SD) & Mean & (SD) & Mean & $(\mathrm{SD})$ \\
\hline Age (years) & 26.7 & (3.6) & 27.6 & (3.5) & 27.1 & (3.6) \\
\hline \multicolumn{7}{|l|}{ Working environment } \\
\hline Night duty (days/month) & 3.8 & $(2.2)$ & 3.3 & $(2.3)$ & 3.6 & $(2.3)$ \\
\hline Working hours (h/day) & 11.9 & (2.7) & 10.9 & $(1.7)$ & 11.5 & $(2.4)$ \\
\hline
\end{tabular}

$\mathrm{n}$ : number of respondents. SD standard deviation

Logistic regression analysis of burnout using gender, frequency of night duty, working hours, age, work controllability, and the SOC10 as independent variables indicated that working hours (odds ratio [OR]: 1.315, 95\% confidence interval $[\mathrm{CI}]: 1.057-1.636, p=0.014)$ and the SOC10 (OR: 0.928, 95\% CI: 0.882-0.976, $p=0.004$ ) were significant factors for having burnout. The SOC10 (OR: 0.918, 95\% CI: $0.854-0.986, p=0.018)$ and frequency of night duty (OR: $0.615,95 \%$ CI: $0.388-0.974, p=0.038$ ) were significant variables for burnout for respondents in the third and fifteenth months of the residency program, respectively.

\section{MBI subscale scores at different training phases}

At the third month, 32 (51.6, $97.0 \%$ of burned out residents), 16 (25.8, 48.5\% of burned out residents), and 47 (75.8\%) residents were judged as having abnormally high scores on the MBI-EX and MBI-CY, and low scores on the MBI-PE, respectively (Table 5).

At the fifteenth month, 12 (34.3, 80.0\% of burned out residents), 9 (25.7, 60.0\% of burned out residents), and $30(85.7 \%)$ residents were judged as having abnormally high scores on the MBI-EX and MBI-CY, and low scores on the MBI-PE, respectively.

Chi-square test and t-test indicated that the frequency of abnormal subscale scores and average subscale scores between the third and fifteenth months were not significantly different.

\section{MBI subscale scores, SOC10 score, and working hours}

The average SOC10 score of the 97 residents was 45.0 (standard deviation 10.1) (Table 3). Thirty residents $(62.5 \%)$ in the low SOC group (SOC10 $\leq 45, n=48$ ) and $18(36.7 \%)$ in the high SOC group (SOC10 $>45, n=49)$ were judged as having burnout (Table 4).

The MBI subscale scores in the low and high SOC groups in the third and fifteenth months are shown in Table 6. MBI-EX, -CY, and -PE scores between the low and high SOC groups at the third month, and MBI-CY, and -PE scores between the low and high SOC groups at the fifteenth month were significantly different by $\mathrm{t}$-test $(p<0.05)$.

In the low SOC group, the Pearson correlation coefficients between working hours and all three MBI subscale scores were significant in the third month (MBI-EX: $r=$ 0.47, $p=0.007$; MBI-CY: $r=0.39, p=0.029$; MBI-PE: $r=-$ $0.44, p=0.012$ ), but not in the fifteenth. In the high SOC group, working hours correlated with only MBI-PE in the third month $(r=0.36, p=0.049)$ (Table 6).

To analyze the relationship between working hours, SOC scores, and MBI subscale scores, the respondents were divided into four groups: $\leq 9 \mathrm{~h}$ (19 residents), $>9$ to $11 \mathrm{~h}$ ( 29 residents), $>11$ to $13 \mathrm{~h}$ (32 residents), and $>13 \mathrm{~h}$ (17 residents) per day.

As shown in Fig. 1, two-way analysis of variance with working hours and SOC scores as factors of the MBI-EX score revealed that working hours and SOC scores were significant variables in the third and fifteenth months, respectively. Regarding the MBI-CY and MBI-PE scores, SOC was a significant variable in both the third and fifteenth months. The MBI-PE score in the high SOC group was higher (more professional efficacy) in longer working hour groups, whereas the MBI-PE score of the low SOC group was lower (less professional efficacy) in longer working hour groups.

\section{Discussion}

In the present study, $49.5 \%$ of Japanese residents were judged as having burnout, and working hours was significantly related to burnout. However, the residents in this study, who worked an average of $63.3 \mathrm{~h}$ per week, showed a high frequency of burnout similar to residents in the United States who worked an average of $80 \mathrm{~h}$ per week, which indicates that working hour regulations alone might not be adequate for reducing burnout.

The MBI-EX, which is composed of five items, e.g., 'I feel emotionally drained from my work', and 'I feel tired when I get up in the morning and have to face another 
Table 2 Promax-rotated pattern/structure coefficients for each factor, extracted communalities $\left(h^{2}\right)$, and eigenvalues for SOC and $\mathrm{MBI}$ factor analysis of scores from 97 residents

\begin{tabular}{|c|c|c|c|c|c|c|c|}
\hline \multirow[t]{2}{*}{ Item } & \multicolumn{7}{|l|}{ Factor } \\
\hline & 1 & 2 & 3 & 4 & 5 & 6 & $h^{2}$ \\
\hline MBI16 & 0.880 & -0.087 & -0.012 & 0.086 & 0.090 & -0.027 & 0.757 \\
\hline MBI10 & 0.873 & -0.181 & -0.004 & 0.164 & 0.041 & -0.102 & 0.735 \\
\hline MB|11 & 0.768 & 0.038 & -0.154 & -0.068 & -0.011 & 0.080 & 0.552 \\
\hline MBI7 & 0.757 & 0.079 & 0.054 & -0.052 & 0.025 & 0.002 & 0.639 \\
\hline MBI12 & 0.683 & 0.137 & -0.103 & -0.218 & 0.056 & 0.272 & 0.625 \\
\hline MBI5 & 0.561 & 0.163 & 0.076 & -0.205 & -0.180 & -0.092 & 0.487 \\
\hline SOC4 & 0.298 & 0.162 & 0.157 & -0.070 & 0.056 & 0.189 & 0.209 \\
\hline XSOC10 & 0.271 & -0.198 & 0.018 & -0.061 & 0.017 & -0.202 & 0.187 \\
\hline MBI2 & -0.026 & 0.906 & -0.063 & -0.089 & 0.044 & 0.036 & 0.774 \\
\hline MBI1 & 0.013 & 0.821 & -0.069 & 0.001 & 0.000 & 0.084 & 0.686 \\
\hline MBI6 & 0.047 & 0.781 & 0.207 & 0.194 & -0.019 & 0.195 & 0.619 \\
\hline MBI3 & -0.049 & 0.746 & -0.009 & 0.094 & -0.009 & -0.138 & 0.728 \\
\hline MBI4 & -0.004 & 0.645 & -0.054 & 0.253 & 0.009 & -0.109 & 0.720 \\
\hline SOC12 & -0.027 & 0.144 & 0.783 & -0.245 & -0.048 & 0.109 & 0.767 \\
\hline SOC9 & -0.031 & -0.067 & 0.769 & 0.088 & 0.078 & -0.089 & 0.575 \\
\hline SOC8 & 0.118 & -0.048 & 0.718 & 0.007 & -0.031 & -0.352 & 0.663 \\
\hline SOC5 & -0.239 & -0.126 & 0.645 & 0.069 & 0.009 & 0.106 & 0.427 \\
\hline SOC13 & 0.001 & 0.176 & 0.624 & -0.194 & -0.008 & -0.061 & 0.463 \\
\hline SOC6 & 0.301 & -0.284 & 0.421 & 0.265 & -0.203 & 0.077 & 0.375 \\
\hline SOC11 & 0.095 & -0.036 & 0.365 & -0.078 & 0.212 & -0.315 & 0.370 \\
\hline MBI15 & -0.108 & 0.014 & -0.067 & 0.787 & 0.087 & 0.035 & 0.728 \\
\hline MBI8 & -0.019 & 0.246 & 0.043 & 0.762 & 0.044 & -0.112 & 0.810 \\
\hline MBI14 & -0.049 & -0.035 & -0.143 & 0.717 & 0.018 & 0.187 & 0.624 \\
\hline MBI9 & -0.001 & 0.157 & 0.017 & 0.716 & -0.051 & -0.142 & 0.720 \\
\hline MBI13 & 0.212 & 0.38 & 0.010 & 0.421 & -0.090 & -0.064 & 0.473 \\
\hline XSOC2 & 0.147 & 0.020 & -0.153 & 0.047 & 0.815 & -0.133 & 0.633 \\
\hline XSOC3 & -0.122 & -0.009 & 0.162 & 0.037 & 0.735 & 0.044 & 0.604 \\
\hline XSOC1 & 0.057 & 0.001 & 0.264 & -0.076 & 0.410 & 0.080 & 0.387 \\
\hline XSOC7 & 0.123 & -0.130 & -0.048 & -0.420 & 0.005 & 0.468 & 0.593 \\
\hline Rotated sums of squared loadings & 5.375 & 5.328 & 5.490 & 6.320 & 2.461 & 1.324 & \\
\hline
\end{tabular}

MBI Maslach Burnout Inventory, SOC Sense of Coherence scale, XSOC reverse coding item of SOC, MBIx MBI item number x, SOCy SOC item number y We used the main factor method to extract factors

We defined a high factor loading as $\geq 0.4$. Factor analysis was performed by exploratory analyses

Table 3 Residents' mean scores for the MBI-GS subscales and SOC10

\begin{tabular}{|c|c|c|c|c|c|c|c|}
\hline & \multicolumn{2}{|c|}{ Third month $(n=62)$} & \multicolumn{2}{|c|}{ Fifteenth month $(n=35)$} & \multicolumn{2}{|c|}{ Total $(n=97)$} \\
\hline & & Mean & SD & Mean & SD & Mean & SD \\
\hline \multirow[t]{3}{*}{ MBI } & EX & 16.0 & 7.0 & 13.6 & 7.0 & 15.2 & 7.1 \\
\hline & $\mathrm{CY}$ & 7.4 & 6.5 & 8.3 & 7.5 & 7.7 & 6.9 \\
\hline & PE & 16.9 & 8.0 & 15.4 & 6.9 & 16.4 & 7.6 \\
\hline \multicolumn{2}{|c|}{ SOC10 } & 45.0 & 10.0 & 45.0 & 10.5 & 45.0 & 10.1 \\
\hline
\end{tabular}

MBI Maslach Burnout Inventory, EX emotional exhaustion, $C Y$ cynicism, $P E$ professional efficacy; SOC10: scores on the Sense of Coherence scale, excluding three items that were classified into the Maslach Burnout Inventory subscales. n: number of respondents. SD standard deviation day on the job', indicates decreased working vitality, that is, a low state of mental, creative, and physical energy levels. Meanwhile, the MBI-CY, which is composed of five items, e.g., 'I've become less interested in my work since I started this job', and 'I doubt the significance of my work', indicates decreased enthusiasm, that is, a low degree of interest in working. Our data indicated that half of Japanese residents were judged as having burnout as early as the third month of training, and among those burned out residents, $97.0 \%$ were emotionally exhausted and $48.4 \%$ were abnormally cynical.

Teunissen et al. pointed out a problem at the transitional phase from undergraduate education to postgraduate 
Table 4 Number and percentage of burnout according to the participants' gender and working environment

\begin{tabular}{|c|c|c|c|c|c|c|c|c|c|}
\hline \multirow[b]{3}{*}{ Variable } & \multicolumn{3}{|l|}{ Third month } & \multicolumn{3}{|c|}{ Fifteenth month } & \multicolumn{3}{|l|}{ Total } \\
\hline & \multirow{2}{*}{$\begin{array}{l}\text { Respondents } \\
\mathrm{n}\end{array}$} & \multicolumn{2}{|c|}{ Burnout } & \multirow{2}{*}{$\begin{array}{l}\text { Respondents } \\
\text { n }\end{array}$} & \multicolumn{2}{|c|}{ Burnout } & \multirow{2}{*}{$\begin{array}{l}\text { Respondents } \\
\text { n }\end{array}$} & \multicolumn{2}{|c|}{ Burnout } \\
\hline & & $n$ & $(\%)$ & & $n$ & (\%) & & $n$ & $(\%)$ \\
\hline All & 62 & 33 & $(53.2)$ & 35 & 15 & $(42.9)$ & 97 & 48 & $(49.5)$ \\
\hline Male & 37 & 22 & $(59.5)$ & 26 & 9 & $(34.6)$ & 63 & 31 & $(49.2)$ \\
\hline Female & 25 & 11 & $(44.0)$ & 9 & 6 & $(66.7)$ & 34 & 17 & $(50.0)$ \\
\hline \multicolumn{10}{|c|}{ Night duty (days/month) } \\
\hline$\leq 2$ & 15 & 5 & (33.3) & 10 & 6 & $(60.0)$ & 25 & 11 & $(44.0)$ \\
\hline$\leq 4$ & 23 & 13 & $(56.5)$ & 16 & 8 & $(50.0)$ & 39 & 21 & $(53.8)$ \\
\hline$\leq 6$ & 17 & 10 & $(58.8)$ & 7 & 1 & $(14.3)$ & 24 & 11 & $(45.8)$ \\
\hline$>6$ & 5 & 4 & $(80.0)$ & 2 & 0 & (0) & 7 & 4 & $(57.1)$ \\
\hline \multicolumn{10}{|c|}{ Working hours (h/day) } \\
\hline$\leq 9$ & 11 & 4 & $(36.4)$ & 8 & 1 & $(12.5)$ & 19 & 5 & $(26.3)$ \\
\hline$\leq 11$ & 18 & 8 & $(44.4)$ & 11 & 5 & $(45.5)$ & 29 & 13 & $(44.8)$ \\
\hline$\leq 13$ & 19 & 10 & (52.6) & 13 & 7 & $(53.8)$ & 32 & 17 & $(53.1)$ \\
\hline$>13$ & 14 & 11 & (78.6) & 3 & 2 & $(66.7)$ & 17 & 13 & $(76.5)$ \\
\hline \multicolumn{10}{|c|}{ Existence of somebody to consult with } \\
\hline Yes & 57 & 30 & (52.6) & 33 & 14 & $(42.4)$ & 90 & 44 & $(48.9)$ \\
\hline No & 5 & 3 & $(60.0)$ & 2 & 1 & $(50.0)$ & 7 & 4 & $(57.1)$ \\
\hline \multicolumn{10}{|c|}{ Has ways to release one's stress } \\
\hline Yes & 57 & 30 & (52.6) & 31 & 11 & $(35.5)$ & 88 & 41 & $(46.6)$ \\
\hline No & 4 & 3 & $(75.0)$ & 3 & 3 & $(100.0)$ & 7 & 6 & $(85.7)$ \\
\hline \multicolumn{10}{|c|}{ Feels adequate reward for own work } \\
\hline Yes & 56 & 28 & $(50.0)$ & 30 & 13 & $(43.3)$ & 86 & 41 & $(47.7)$ \\
\hline No & 6 & 5 & (83.3) & 5 & 2 & $(40.0)$ & 11 & 7 & (63.6) \\
\hline \multicolumn{10}{|c|}{ Work controllability } \\
\hline Can & 46 & 20 & $(43.5)$ & 24 & 10 & $(41.7)$ & 70 & 30 & (42.9) \\
\hline Cannot & 16 & 13 & (81.3) & 11 & 5 & $(45.5)$ & 27 & 18 & $(66.7)$ \\
\hline \multicolumn{10}{|l|}{ soc10 } \\
\hline$\leq 45$ & 32 & 20 & $(62.5)$ & 16 & 10 & $(62.5)$ & 48 & 30 & (62.5) \\
\hline$>45$ & 30 & 13 & (43.3) & 19 & 5 & $(26.3)$ & 49 & 18 & (36.7) \\
\hline
\end{tabular}

Burnout: respondents who were diagnosed as burnout by the Maslach Burnout Inventory (emotional exhaustion $\geq 16$ and/or cynicism $\geq 11$ )

$\mathrm{n}$ : number of respondents. SOC10: scores on the Sense of Coherence scale, excluding three items that were classified into the Maslach Burnout Inventory subscales

residency training [38]. Residents were under greater stresses caused by interacting with patients and medical staff, learning new material in a more self-directed way, and bearing many responsibilities that accompany the delivery of patient care and the need to take on increasingly more tasks independently [38]. Residents were mentally fatigued and had restrained emotions during this phase.

Burnout among Japanese medical students, whose clinical training is usually finished 8 months prior to graduation, was reported as being $13.3 \%$ for males and $31.3 \%$ for females [39]. When these students start residency training in a teaching hospital, there is a substantial change in their professional role as a licensed medical doctor and in their personal life. Encountering a new environment might be a cause of burnout among Japanese residents at the early phase of training, since working hours, one of the environmental factors, was a significant factor of MBI subscale scores at the third month of training.

Among burned out residents at the fifteenth month, $80 \%$ were emotionally exhausted, and $60 \%$ were abnormally cynical. At this point, they tended to have low enthusiasm and view things cynically in addition to having low interest in working compared to burned out residents at the third month.

Cynicism in the later phase of training has previously been reported [40], and our data indicate that residents with low stress coping ability might have this tendency. 
Table 5 Number of respondents who had abnormal MBI subscale scores in the third and fifteenth months of their residency program

\begin{tabular}{|c|c|c|c|c|c|c|}
\hline & \multicolumn{2}{|c|}{ Third month } & \multicolumn{2}{|c|}{ Fifteenth month } & \multicolumn{2}{|c|}{ Total } \\
\hline & $n$ & (\%) & $\mathrm{n}$ & (\%) & $n$ & (\%) \\
\hline High MBI-EX & 32 & (51.6) & 12 & (34.3) & 44 & $(45.4)$ \\
\hline High MBI-CY & 16 & (25.8) & 9 & $(25.7)$ & 25 & $(25.8)$ \\
\hline Low MBI-PE & 47 & (75.8) & 30 & $(85.7)$ & 77 & (79.4) \\
\hline Burnout & 33 & $(53.2)$ & 15 & $(42.9)$ & 48 & (49.5) \\
\hline Total & 62 & (100) & 35 & (100) & 97 & (100) \\
\hline
\end{tabular}

High MBI-EX: residents whose Maslach Burnout Inventory (MBI) emotional exhaustion score was $\geq 16$

High MBI-CY: residents whose MBI cynicism score was $\geq 11$

Low MBI-PE: residents whose MBI professional efficacy score was $\leq 25$

Burnout: respondents who were diagnosed as having burnout by High MBI-EX and/or High MBI-CY

$\mathrm{n}$ : number of respondents

Burnout as judged by the MBI indicates an individual's state at the time of inquiry. On the other hand, a resident's stress coping ability as evaluated by the SOC scale is fixed to some extent in early adulthood, and might be only slightly changeable because of life experiences [25]. As previously reported [23, 26], resident groups with high SOC scores showed a low frequency of burnout as judged by emotional exhaustion and cynicism. In addition, these residents showed high professional efficacy, regardless of the training phase. Furthermore, longer working hours did not worsen their emotional exhaustion or cynicism; rather, professional efficacy was increased in this group, in contrast to the low SOC group, in which professional efficacy decreased.

Kroninger-Jungaberle et al. reported that the concepts of SOC and self-efficacy foster resilience [41]. Mastery experience has also been reported to increase selfefficacy [42]. Our data indicate that residents with high stress coping ability can increase their self-efficacy by gaining more clinical experience, as indicated by working hours, thereby obtaining resilience.

A previous report pointed out that limiting working hours is obviously effective for the prevention of burnout, but there was some discussion that excessive restrictions might hinder professional development [29, 43]. We found that appropriate working hours for effective training might vary among individuals, and that in addition to supportive programs for residents, personalized programs compatible with his/her stress coping ability and current burnout status would be required.

Residents are in danger of burnout at the very early phase of training, and the expression of burnout might change as time passes. Screening residents using the SOC scale could help teaching staff and program directors identify residents at high risk of burnout and provide necessary support early for its prevention without excessively limiting clinical experience for those at low risk.

\section{Limitations}

The hospital targeted in the present study was randomly selected from among those throughout the entire country, but the response rate and number of samples for analyses were low. We could not exclude the possibility that burned out residents did not respond to the questionnaire, or that the prevalence of burnout was higher than that identified in our analyses. In addition, we used a cross-sectional survey design with two data collection points. Thus, the relationship between working hours and burnout at a later phase of a training program

Table 6 Average MBI subscale scores in the low and high SOC groups and Pearson correlation coefficients with working hours

\begin{tabular}{|c|c|c|c|c|c|c|c|c|c|c|c|c|c|c|c|c|c|}
\hline \multirow[b]{3}{*}{ MBI } & \multirow[b]{3}{*}{ Group } & \multicolumn{8}{|c|}{ Third month } & \multicolumn{8}{|c|}{ Fifteenth month } \\
\hline & & \multirow[b]{2}{*}{$\mathrm{n}$} & \multirow[b]{2}{*}{ Mean } & \multirow[b]{2}{*}{ SD } & \multicolumn{2}{|l|}{$t$-test } & \multicolumn{3}{|c|}{$\begin{array}{l}\text { Pearson correlation with } \\
\text { working hours }\end{array}$} & \multirow[b]{2}{*}{$\mathrm{n}$} & \multirow[b]{2}{*}{ Mean } & \multirow[b]{2}{*}{ SD } & \multicolumn{2}{|l|}{ t-test } & \multicolumn{3}{|c|}{$\begin{array}{l}\text { Pearson correlation with } \\
\text { working hours }\end{array}$} \\
\hline & & & & & $\mathrm{p}(d)$ & $1-\beta$ & $r$ & $p$ & $1-\beta$ & & & & $\mathrm{p}(d)$ & $1-\beta$ & $r$ & $\mathrm{p}$ & $1-\beta$ \\
\hline \multirow[t]{2}{*}{$-E X$} & Low SOC & 32 & 17.7 & 6.8 & \multirow{2}{*}{$\begin{array}{l}0.048^{*} \\
(0.51)\end{array}$} & \multirow[t]{2}{*}{0.51} & 0.47 & $0.007^{* *}$ & 0.79 & 16 & 15.9 & 6.8 & \multirow{2}{*}{$\begin{array}{l}0.083 \\
(0.61)\end{array}$} & \multirow[t]{2}{*}{0.41} & 0.17 & 0.525 & 0.15 \\
\hline & High SOC & 30 & 14.2 & 6.9 & & & 0.28 & 0.134 & 0.32 & 19 & 11.7 & 6.8 & & & 0.17 & 0.479 & 0.15 \\
\hline \multirow[t]{2}{*}{$-C Y$} & Low SOC & 32 & 9.9 & 7.2 & \multirow{2}{*}{$\begin{array}{l}0.001^{* *} \\
(0.89)\end{array}$} & \multirow[t]{2}{*}{0.93} & 0.39 & $0.029^{*}$ & 0.61 & 16 & 12.9 & 8.6 & \multirow{2}{*}{$\begin{array}{l}0.000^{* *} \\
(1.31)\end{array}$} & \multirow[t]{2}{*}{0.96} & 0.14 & 0.602 & 0.12 \\
\hline & High SOC & 30 & 4.6 & 4.4 & & & 0.14 & 0.466 & 0.11 & 19 & 4.4 & 3.1 & & & 0.09 & 0.708 & 0.08 \\
\hline \multirow[t]{2}{*}{$-P E$} & Low SOC & 32 & 14.3 & 7.1 & \multirow{2}{*}{$\begin{array}{l}0.008^{* *} \\
(0.70)\end{array}$} & \multirow[t]{2}{*}{0.78} & -0.44 & $0.012^{*}$ & 0.73 & 16 & 12.9 & 6.4 & \multirow{2}{*}{$\begin{array}{l}0.049^{*} \\
(0.70)\end{array}$} & \multirow[t]{2}{*}{0.51} & -0.19 & 0.474 & 0.18 \\
\hline & High SOC & 30 & 19.7 & 8.1 & & & 0.36 & $0.049^{*}$ & 0.51 & 19 & 17.5 & 6.8 & & & 0.24 & 0.315 & 0.25 \\
\hline
\end{tabular}

MBI-EX Maslach Burnout Inventory-emotional exhaustion

$M B I-C Y$ Maslach Burnout Inventory-cynicism

$M B I-P E$ Maslach Burnout Inventory-professional efficacy

Low SOC: Respondents whose score on the 10-item Sense of Coherence Scale was $\leq 45$

High SOC: Respondents whose score on the 10-item Sense of Coherence Scale was $>45$

$\mathrm{n}$ : number of respondents. SD standard deviation

${ }^{*} p<0.05 ;{ }^{* *} p<0.01$ : Significant difference in average MBI subscale scores between the low and high SOC groups based on a $t$-test, and in Pearson correlation analysis of MBI subscale scores and working hours

$d$ :Cohen's $d$ effect size

1- $\beta$ : Power of analysis

r: Pearson correlation coefficient 


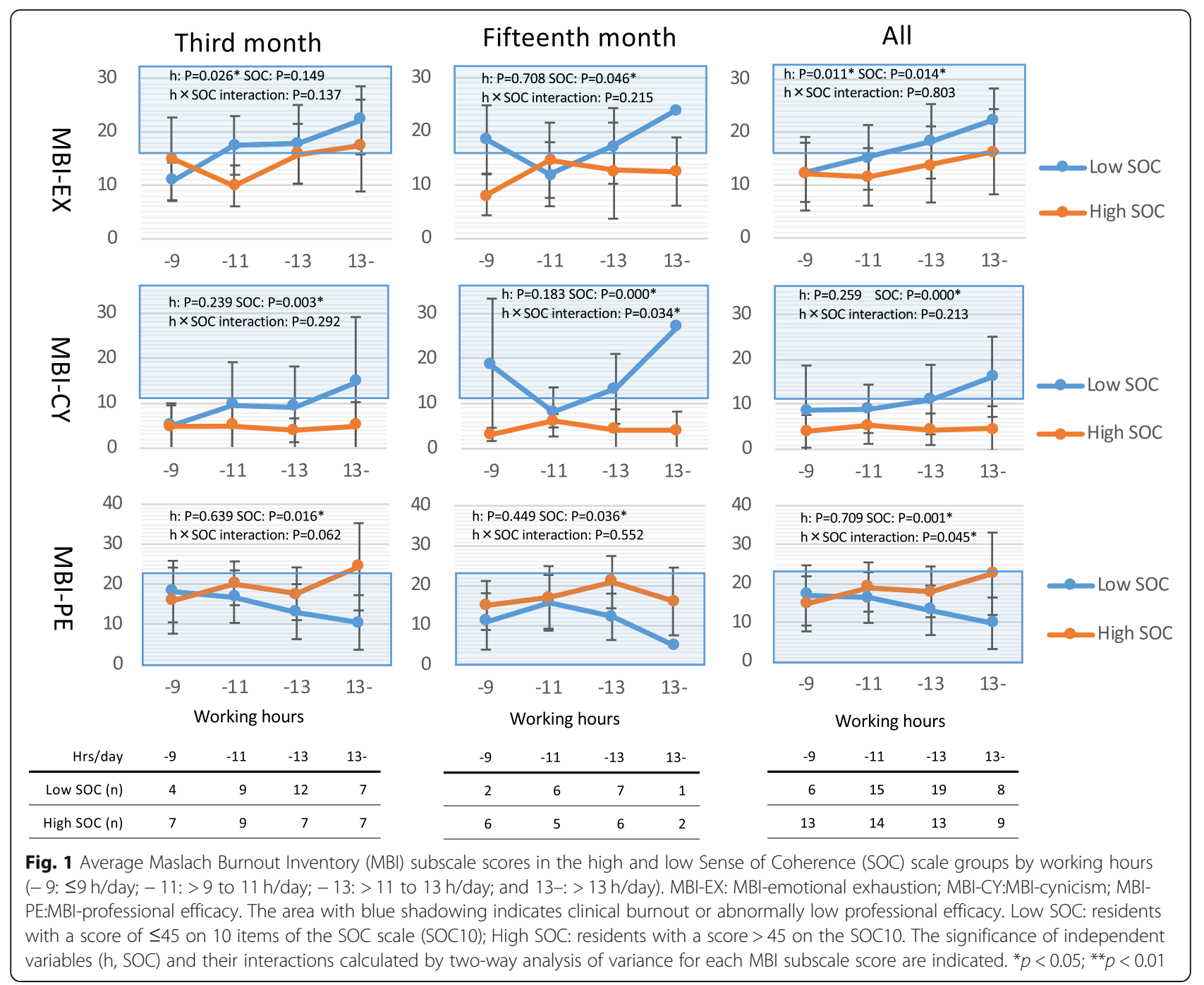

remains somewhat unclear because long working hours could be a cause of burnout, and also shortened as a result of burnout. To confirm the changes in burnout status during the training period, it will be necessary to follow these individuals in a cohort study.

Furthermore, this was a survey of residents in a Japanese training program; additional research in other regions and with different training systems is required before our results can be generalized.

\section{Conclusions}

Half of the Japanese residents analyzed in the present study were emotionally restrained and judged as having burnout in the third month of training. As previously reported, working hours and stress coping ability as evaluated by the SOC were both independent influential factors for burnout. In addition, we found that residents with high stress coping ability maintained their interest and enthusiasm for working and obtained professional efficacy under longer working hours, whereas residents with low stress coping ability were liable to experience burnout under the same working conditions. Individual stress coping ability could therefore be valuable information for fostering a suitable training environment.

\section{Abbreviations}

MBI: Maslach Burnout Inventory; SOC: Sense of Coherence; MBI-GS: Maslach Burnout Inventory-General Survey; MBI-EX: MBI-GS subscale emotional exhaustion; MBI-CY: MBI-GS subscale cynicism; MBI-PE: MBI-GS subscale professional efficacy; OR: Odds ratio; Cl: Confidence interval

\section{Acknowledgments}

We would like to thank the respondents and everyone who supported this research.

\section{Authors' contributions}

SK was responsible for designing the questionnaire, performing the statistical analyses, and drafting the initial manuscript; MT made substantial revisions to the manuscript and supported SK in its development, including the search process; KT was responsible for the methodology of the statistical analyses. All authors have read and approved the final version of this manuscript for submission. 


\section{Funding}

None.

\section{Availability of data and materials}

Data except MBI can be disclosed within the scope of ethical codes according to requests to Masami Tagawa.

\section{Ethics approval and consent to participate}

This research project was approved by the Graduate School of Medical and Dental Science, Kagoshima University (No. 638, 180,122).

All target residents received a written explanation of the study protocol and the voluntary nature of participation. Residents who consented to participate were asked to return the completed questionnaire. Informed consent was assumed to be obtained when the participants returned a completed questionnaire

MT obtained a license to use this scale in this study and that a copy of the license has been made available to the Editor of the journal.

\section{Consent for publication}

All target residents received a written explanation of the possible publication of the research findings. Residents who consented to participate were asked to return the completed questionnaire.

\section{Competing interests}

The authors declare that they have no competing interests.

\section{Author details}

${ }^{1}$ Center for Innovation in Medical and Dental Education, Graduate School of Medical and Dental Sciences, Kagoshima University, 8-35-1 Sakuragaoka, Kagoshima 890-8544, Japan. 'Osumi Kanoya Hospital, 6081-1 Shinkawacho, Kanoya, Kagoshima 893-0015, Japan. ${ }^{3}$ Department of Psychology, Faculty of Law, Economics, and Humanities, Kagoshima University, 1-21-30 Korimoto, Kagoshima 890-0065, Japan.

\section{Received: 22 July 2019 Accepted: 2 July 2020}

\section{Published online: 13 July 2020}

\section{References}

1. Maslach C, Jackson SE. The measurement of experienced burnout. J Occup Behav. 1981;2:99-113.

2. Maslach C, Schaufeli WB, Leiter MP. Job burnout. Ann Rev Psychol. 2001;52: 397-422.

3. Prins JT, Gazendam-Donofrio SM, Tubben BJ, Van der Heijden FMMA, Van der Wiel HBM, Hoekstra-Weebers JEHM. Bunrout in medical residents: a review. Med Educ. 2007;41:788-800

4. Escriba-Aguir V, Martin-Baena D, Perez-Hoyos S. Psychosocial work emvironment and burnout among emergency medical and nursing staff. Int Arch Occup Environ Health. 2006:80:127-33.

5. Shanafelt TD, Bradly KA, Wipf JE, Back AL. Burnout and self-reported patient care in an internal medicine residency program. Ann Intern Med. 2002;136: 358-67.

6. Willcock SM, Daly MG, Tannant CC, Allard BJ. Burnout and psychiatric morbidity in new medical graduates. MJA. 2004;181(7):357-60.

7. Maslach C, Leiter MP. The truth about burnout. San Francisco: Jossey-Bass; 1997.

8. Blanchard P, Truchot D, Albiges-Sauvin L, Dewas S, Pointreau Y, Rodrigues $\mathrm{M}$, et al. Prevalence and causes of burnout amongst oncology residents: a comprehensive nationwide cross-sectional study. Eur J Cancer. 2010;46(15) 2708-15.

9. Fonseca M, Sanclemente G, Hernández C, Visiedo C, Bragulat E, Miró O. Resident, duties and burnout syndrome. Rev Clin Esp. 2010;210(5):209-15.

10. Embriaco N, Azoulay E, Barrau K, Kentish N, Pochard F, Loundou A, et al. High level of burnout in intensivists: prevalence and associated factors. Am J Respir Crit Care Med. 2007:175(7):686-92.

11. Martin S, Arfken CL, Balon R. Comparison of burnout among medical residents before and after the implementation of work hours limits. Acad Psych. 2006;30(4):352-5.

12. Isaksson Ro KE, Tyssen R, Aasland OG. Counselling for burnout in Norwegian doctors: one year cohort study. BMJ. 2008. https://doi.org/10.1136/bmj.a2004.

13. Isaksson Ro KE, Tyssen R, Hoffart A, Sexton H, Aasland OG, Gude T. A threeyear cohort study of the relationships between coping, job stress and burnout after a counselling intervention for help-seeking physicians. BMC Public Health. 2010;27(10):213.

14. Ramanan RA, Taylor WC, Davis RB, Phillips RS. Mentoring matters: mentoring and career preparation in internal medicine residency training. J Gen Intern Med. 2006:21(4):340-5

15. Eckleberry HJ, Lick D, Boura J. An exploratory study of resident burnout and wellness. Acad Med. 2009;84(2):269-77.

16. Ishak WW, Lederer S, Mandili C, Nikravesh R, Seligman L, Vasa M, et al. Burnout during residency training: a literature review. J Grad Med Educ. 2009. https://doi.org/10.4300/JGME-D-09-00054.1.

17. Shadid A, Shadid AM, Shadid A, Almutairi FE, Almotairi KE, Aldarwish T, et al. Stress, burnout, and associated risk factors in medical students. Cureus. 2020;12(1):e6633.

18. Romcevich LA, Reed S, Flowes SR, Kemper KJ, Mahan JD. Mind-body skills training for resident wellness: a pilot study of a brief mindfulness intervention. J Med Educ Curric Dev. 2018. https://doi.org/10.1177// 2382120518773061.e Collection 2018 Jan-Dec.

19. Martin S, Arfken CL, Churchill A, Balon R. Burnout comparison among residents in different medical specialties. Acad Psychiatry. 2004;28(3):240-2.

20. Collier VU, McCue JD, Markus A, Smith L. Stress in medical residency: status quo after a decade of reform? Ann Intern Med. 2002;136(5):384-90.

21. Hillhouse JJ, Adler CM, Walters DN. A simple model of stress, burnout and symptomatology in medical residents: a longitudinal study. Psychol Health Med. 2000;5:63-73.

22. Dahlke AR, Johnson JK, Greenberg CC, Love R, Kreutzer L, Hewitt D, et al. Gender differences in utilization of duty-hour regulations, aspects of burnout, and psychological well-being among general surgery residents in the United States. Ann Surg. 2018;268:204-11.

23. Tsele A, Moulou A, llias I. Burnout versus depression and sense of coherence. Nurs Health Sci. 2001:3:69-71.

24. Cilliers F. Burnout and salutogenic functioning of nurses. Curationis. 2003; 26(1):62-74.

25. Antonovsky A. Unraveling the mystery of health: how people manage stress and stay well. San Francisco: Jossey-Bass Publishers; 1987.

26. Tartas M, Walkiewicz M, Majkowicz M, Budzinski W. Psychological factors determining success in a medical career: a 10-year longitudinal study. Med Teach. 2011;33:e163-72.

27. Gelfand DV, Podnos YD, Carmichael JC, Saltzman DJ, Wilson ES, Williams RA Effect of the 80-hour workweek on resident burnout. Arch Surg. 2004;139: 933-40.

28. Gopal R, Glasheen JJ, Miyoshi TJ, Prochazka AV. Burnout and internal medicine resident work-hour restrictions. Arch Intern Med. 2005;165:2595-600.

29. Hutter MM, Kellogg KC, Ferguson CM, Abbott WM, Warshaw AL. The impact of the 80-hour resident workweek on surgical residents and attending surgeons. Ann Surg. 2006;243:864-75.

30. Goitein L, Shanafelt TD, Wipf JE, Slatore CG, Back AL. The effect of workhour limitations on resident well-being, patient care, and education in an internal medicine residency program. Arch Intern Med. 2005;165:2601-6.

31. Martini S, Arfken CL, Balon R. Comparison of burnout among medical residents before and after the implementation of work hours limits. Acad Psychiatry. 2006:30:352-5.

32. Olson SM, Odo NU, Duran AM, Pereira AG, Mandel JH. Burnout and physical activity in Minnesota internal medicine resident physicians. J Grad Med Educ. 2014; https://doi.org/10.4300/JGME-D-13-00396.

33. Elmore $L C$, Jeffe $D B$, Jin $L$, Award MM, Turnbull IR. National survey of burnout among US general surgery residents. Am Coll Surg. 2016;223(3): 440-51.

34. Mind Garden, Inc. MBI-General Survey (MBI-GS). Copyright (C1996 Wilmar B. Schaufeli, Michael P. Leiter, Christina Maslach, Susan E. Jacson. All rights reserved in all media.

35. Kitaoka K, Masuda S, Ogino K, Nakagawa H. The Maslach burnout inventorygeneral survey (MBI-GS) and the Japanese version. Hokuriku J Public Health. 2011;37(2):34-40.

36. Togari T, Yamazaki Y. Examination of the reliability and factor validity of 13item five-point version sense of coherence scale. Jpn J Health Hum Ecol. 2005:71(4):168-82

37. Schaufeli W, Bakker A, Hoogduin K, Schaap C, Kladler A. On the clinical validity of the Maslach burnout inventory and the burnout measure. Psychol Health. 2001;16(5):565-82.

38. Teunissen PW, Westerman M. Opportunity or threat: the ambiguity of the consequences of transitions in medical education. Med Educ. 2011;45:51-9. 
39. Inaba R, Sugiura $\mathrm{H}$. Survey on burnout and life-style among medical and phamacy students. Jpn Health Medi Assoc. 2012;20(4):228-33.

40. Michels P, Probst J, Godenick M, Palesch Y. Anxiety and anger among family practice residents: a South Carolina family practice research consortium study. Acad Med. 2003;78:69-79.

41. Kroninger-Jungaberle $\mathrm{H}$, Grevenstein D. Development of salutogenetic factors in mental health-Antonovsky's sense of coherence and Bandura's self-efficacy related to Derogatis' symptom check list (SCL-90-R). Health Qual Life Outcomes. 2013. https://doi.org/10.1186/1477-7525-11-80.

42. Bandura A. Self-efficacy. The experiences of control. New York: WH Freeman and Company; 1997.

43. Antiel RM, Reed DA, Van Arendonk KJ, Wightman SC, Hall DE, Porterfield JR. Effect of duty hour restrictions on core competencies, education, quality of life, and burnout among general surgery interns. JAMA Surg. 2013;148(5): 448-55.

\section{Publisher's Note}

Springer Nature remains neutral with regard to jurisdictional claims in published maps and institutional affiliations.

Ready to submit your research? Choose BMC and benefit from:

- fast, convenient online submission

- thorough peer review by experienced researchers in your field

- rapid publication on acceptance

- support for research data, including large and complex data types

- gold Open Access which fosters wider collaboration and increased citations

- maximum visibility for your research: over $100 \mathrm{M}$ website views per year

At BMC, research is always in progress.

Learn more biomedcentral.com/submissions 